\title{
An analysis of the causes of lagging development and the prospects of Laos e-commerce
}

\author{
Yue Yang* \\ International Business School \\ Yunnan University of Finance and Economics \\ Kunming, China \\ 532630837@qq.com \\ Hong Yi \\ International Business School \\ Yunnan University of Finance and Economics \\ Kunming, China \\ ynyihong@126.com
}

Wei Wang

\author{
International Business School \\ Yunnan University of Finance and Economics Kunming, \\ Kunming, China \\ 704234551@qq.com
}

\section{Wen Zhang}

International Business School

Yunnan University of Finance and Economics

Kunming, China

zhangxiaowen615@163.com

\section{Li Huang}

International Business School

Yunnan University of Finance and Economics

Kunming, China

\begin{abstract}
The development of e-commerce in Laos is at the initial stage, but the development momentum is better and shows a steady upward trend. In this paper, through the local research and questionnaire survey conducted in Laos, obtained a single hand data, with accessing to the relevant literature, analyzed the relevant profiles of Laos e-commerce. Found that the current development process of Laos e-commerce has a lot of problems, such as the payment system is not perfect, the logistics system is not perfect, low use of intelligent machines, electricity laws and regulations have not yet established and other issues, but also see the development prospects and opportunities of Laos e-commerce.
\end{abstract}

Keywords - Laos; e-commerce

\section{INTRODUCTION}

"Internet + " is a new form of development of the Internet, and is inseparable with our all aspects of production and life. The Internet + traditional foreign trade, prompted the cross-border e-commerce, cross-border e-commerce makes up for the data lack and transparency of traditional foreign trade, and uses the Internet to expand the scope of foreign trade industry, promotes the transaction speed and reduces transaction cost. China and Laos had good trade since ancient times, after the completion of the railway, China and Laos will be more closely, so the study of cross-border e-commerce between China and Laos without delay. Laos' cross-border e-commerce is in the initial development currently, has not yet carried out other models in addition to $\mathrm{B} 2 \mathrm{C}$ cross-border e-commerce, and the existing literature is lack of the research of the cross-border e-commerce research between China and Laos. China is the powerful nation of cross-border e-commerce, and $\mathrm{B} 2 \mathrm{C}$ cross-border e-commerce transactions reached 751.2 billion $\mathrm{RMB}$ in 2015 , up $69 \%$ over last year. 2015 B2C cross-border e-commerce transactions reached 30 million RMB in Laos, although starting late, the developmentmomentum is better and into a steady upward trend. While the scale of $\mathrm{B} 2 \mathrm{C}$ cross-border electricity in Southeast Asia is only 1\%, but the region is expected to reach the twice of China's cross-border retail electricity transactions in the next 4-5 years, Laos as the member of the Southeast Asia will also take the lead in the development of cross-border electricity business.

Although there are no scholars to study Laos e-commerce, but some scholars study the Southeast Asian e-commerce. Le Van Huy \& Frantz Rowe mainly used the TOE model to analyze the external factors and internal factors influencing the development and transformation of the e-commerce of small and medium-sized enterprises in Vietnam [1]. Khuong Le-Nguyen and Yue Guo introduced the concept and model of e-commerce, and suggested that Southeast Asian countries should choose to carry out e-commerce [2]. Phetcharaburanin found that although the development of e-commerce is good in Thailand, but there are still many problems, he believes the government needs to strengthen the legal system on e-commerce in Thailand to regulate the development of e-commerce [3]

\section{The DEVELOPMENT OVERVIEW OF LAOS E-COMMERCE}

\section{A. payment method}

The main types of e-commerce settlement are divided into three categories: the first is the traditional bank-backed payment, Laos Bank card holding rate is low, less than $10 \%$, and the number of ATM and POS Business is less than 4000 units. In the Laos, micro-financial institutions can be found everywhere and undertake foreign exchange conversion, remittances, loans, exchange of money and other business, these small micro-financial institutions have been able to

* Corresponding author 
better replace the bank [4]. The second category is to rely on third-party payment platform, China uses the third-party payment platforms such as Alipay, WeChat, etc., but these platforms are not yet popular in Laos. The third category is cash on delivery, it is a payment method that Laos use the most, has the highest degree of penetration in Laos, this payment is relatively simple and safe [5].

\section{B. Logistics status}

Laos is not next the sea, and the domestic transport infrastructure is backward, land transport is the main mode of transport in Laos. The length of highway in Laos is 43604 kilometers, mainly for the dirt road, and there is no expressway. The road transport is the most important in the national transport, about $79 \%$, but the current road standard is far lower than the ASEAN construction standards [6].

Water transport accounted for $18 \%$, is one of the important transports in Laos. The total length of water transport is $3,000 \mathrm{~km}$ in Laos, of which more than $1,800 \mathrm{~km}$ for the Mekong River, the Mekong River is the most important transport water in Laos, connecting 13 cities in Laos and more than 20 terminals located in the Mekong River [7].

\section{Internet infrastructure}

Laos follows the trend of global smart mobile technology closely, and launched 4G network communication technology in 2012, has basically completed the construction of the national communications network, greatly improving the speed of mobile communications. According to the statistics of the Laos national postal telecommunications sector, the domestic telephone usage rate in Laos is $85 \%$ before March 2015 , improves 15 percentage points on the basis of 2010 , and the number of mobile phone users is 4.5 million, of which the smartphone users are 150 Million people. The rate of using cable network is only $21 \%$, improves 10 percentage points on the basis of 2010 .

\section{Laws and regulations related to e-commerce}

Laos has not yet introduced e-commerce laws and regulations, and the government introduced the "Laos Electronic Trading Act" in 2013, it is the only one involving e-commerce laws currently in Laos. The Electronic Transactions Act clearly defines the concept of electronic transactions, which refers to contracting with electronic tools as a medium, as well as the provision and acceptance of e-government business services. The Lao government mentioned that e-commerce is part of electronic transactions in electronic transaction law, e-commerce that the law involved is only refers to the individual or collective use of electronic tools for goods or services transactions [8].

\section{The Problems of THE DEVElopMent OF E-COMMERCE IN LAOS}

\section{A. The payment system is imperfect}

According to my field research, we can see that Laos does not have a perfect payment system. Most people choose cash to pay for e-commerce, and the payment of online banking and mobile banking is not high. The main reason is that the use rate of Lao Bank Card is too low, the lack of bank ATM and outlets are the main reasons for the low utilization rate of Laos bank cards. There is also no third-party payment platform in Laos, Laos payment system is not developed is a major obstacle to the development of Laos e-commerce.

\section{B. Logistics system is not perfect}

Transport infrastructure is inadequate in Laos, mainly for the road is less and the mountain is more in the border, so the high cost of transport means that the price of goods in Laos also very high, but the transport speed is low. Laos mainly rely on land transport trucks and water cargo ships, transport cost is high, and spends a long of time on transport. The current maintenance of road is not good, often need to keep in repair. The slowness of transport led directly to Laos consumers to buy goods, it could make receipt time too long and hinder the development of Laos e-commerce.

\section{Smartphone usage is low}

According to my field research, the problem of communication infrastructure in Laos is mainly about the small range of fiber broadband, the use rate of cable network is only $21 \%$, computer and smart phone usage is low. But Laos $4 \mathrm{G}$ network construction is also better, although the use rate of mobile phones in Laos reached $85 \%$ in 2015 , but the usage of smart phones is low, and the reason is that smart phones are expensive. For the underdeveloped manufacturing, Laos lack the technology that can produce their own mobile phones, mobile phones currently on the market mainly rely on imports. The usage of smart phones directly determines the number of Laos e-commerce consumers.

\section{Electricity laws and regulations have not yet established}

Laos has not yet introduced e-commerce laws and regulations, there are already existing laws related to e-commerce only the "Laos Electronic Trading Act" that introduced in 2013, but this law only refers to the e-commerce, explains the meaning of e-commerce, and did not regulate the behavior of e-commerce. For Laos, the serious lack of e-commerce-related laws and regulations is a problem, so the business and individual behavior does not achieve a good normative role in Laos e-commerce, there is no standard in the event of a dispute.

\section{Prospects For THE DEVElopMent of LAOS E-COMMERCE}

Although there are some problems in the development of Laos e-commerce, there are also opportunities:

First, Laos has the political stability, after joining ASEAN, the Lao government decided to rely on the advantages of Laos, Laos will become the center of ASEAN trade cooperation. And in order to promote economic construction effectively and create favorable conditions for business activities, the Lao government will introduce economic development plan through 2017-2019 to strengthen the economic construction comprehensively, the Lao government's attention to economic construction must conducive to Laos E-Business development. 
Second, the Lao electricity market has many users that need a lot currently, and can be operable, it is able to use the advantages to grow rapidly. Lao population is more young, these people have higher acceptance of e-commerce, and Laos $4 \mathrm{G}$ network construction is more perfect, with suitable for the development of e-commerce.

Third, the Laos plan to do the highway construction line survey and feasibility study from Boten to Vientiane and Vientiane to Baqi. The railway between China and Laos is currently under construction, about $418 \mathrm{~km}$ in Laos, runs through the Mohan port and Luang Prabang, reaches the capital of Laos. The establishment of the first highway and railway in Laos must improve the transport efficiency and reduce the cost of transportation.

Fourth, China has maintained friendly relations with Laos since ancient times, and China and Laos signed the "The Belt and Road Initiative" cooperation documents. China provide personnel training and infrastructure construction assistance and other services for the development of Laos e-commerce, effectively promote the development of Laos e-commerce.

\section{CONCLUSION}

In the communication infrastructure, $4 \mathrm{~g}$ network construction is better in Laos, but the use of intelligent machines is low; Payment settlement to cash on delivery and the number of bank card holders low; Traffic infrastructure is poor, mainly for the less road, and most of them are dirt road, which is vulnerable to rain. The customs authorities have not implemented data sharing, the efficiency of cargo clearance is not high and it is easy to produce goods stranded in the customs situation; There is only the "Laos electronic transactions Law " in Laos, and has not yet introduced e-commerce special laws and regulations policy.
With the development of economic globalization and the promote of "The Belt and Road Initiative", Laos e-commerce is facing obstacles, but also see a lot of development prospects. Laos should seize the opportunity to cooperate closely with China to promote the development of its own e-commerce.

\section{ACKNOWLEDGEMENT}

First of all, I would like to thank my school and college, to provide me with the opportunity to practice abroad for field research in Laos, collecting first-hand data to write for the paper. Then I must thank for my supervisor Yi Hong and Feng Shake, they give me careful guidance when the paper writing. Without their guidance, I could not finish this article, they taught me a lot of things. Finally, I would like to thank my classmates and friends, who have helped me a lot. Because of them, my graduate life can be more exciting.

\section{REFERENCES}

[1] L. Fu, M.G. Wang, "A number of issues and countermeasures between China and Russian about cross-border e-commerce," China Business, 2015, pp. 141-143.

[2] Y.Y. He, "Laos Electronic Trading Act (2013)," Nanyang Information Translation, 2016, pp. 65-78.

[3] L.N. Khuong, G. Yue, "Choosing e-commerce strategies: a case study of eBay.vn partnership," Journal of Information Technology Teching Cases, 2016, pp. 1-14.

[4] W.D. Ke, "Laos road transport development model research," Central South University, 2013.

[5] V.H. Le, R. Frantz, "An Empirical Study of Determinants of E-Commerce Adoption in SMEs in Vietnam: An Economy in Transition," 2012, pp. 32.

[6] Y.J. Lei, J.X. Xuan, "The study about the new cash on delivery payment system under B2C e-commerce,” Hebei enterprises, 2015, pp. 70-71.

[7] Phetharaburanin, "P.E-commerce and Thai society. Pathumwan Academic journal," 2013, pp. 39-45.

[8] S.Y. Pan, "The facilitation study about border trade in agricultural between Laos and Thailand," Guangxi University, 2016. 